Vol. 5, No. 4, 2020

\title{
URBAN PUBLIC TRANSPORT POLICY IN THE CONDITIONS OF COVID-19
}

\author{
Pavlo Popovych $^{1}$, Lubomyr Poberezhny ${ }^{2}$, Oksana Shevchuk ${ }^{1}$, Ihor Vikovych ${ }^{3}$, \\ Olena Skyba ${ }^{4}$, Lubov Poberezhna ${ }^{2}$, Taras Yasrebov ${ }^{5}$ \\ ${ }^{1}$ West Ukrainian National University, \\ 1, Lvivska Str., Ternopil, 46009, Ukraine \\ ${ }^{2}$ Ivano-Frankivsk National Technical University of Oil and Gas, \\ 15, Karpatska Str., Ivano-Frankivsk, 76018, Ukraine \\ ${ }^{3}$ Lviv Polytechnic National University, \\ 12, S. Bandery Str., Lviv, 79013, Ukraine \\ ${ }^{4}$ Ternopil Ivan Pul'uj National Technical University, \\ 56, Ruska Str., Ternopil, 46001, Ukraine \\ ${ }^{5}$ Bogomolets National Medical University, \\ 13, T. Shevchenko Blvd., 01601, Kyiv \\ dlya2906@gmail.com
}

https://doi.org/10.23939/ep2020.04.243

Received:10.10.2020

() Popovych P., Poberezhny L., Shevchuk O., Vikovych I., Skyba O., Poberezhna L., Yasrebov T., 2020

\begin{abstract}
The purpose of the research is formation of passenger transport policy by public transport from the standpoint of determining the level of safety in COVID-19 and passenger comfort with the development of basics for measuring the perception of the most important factors of public transport convenience, minimum discomfort and maximum safety.
\end{abstract}

Methodology. The study was conducted in two stages - inhouse and experimental - the collection and processing of data obtained from the survey of passenger flows. Continuous field research by the tabular method which in comparison with the existing ones is the most time-consuming, but the only one that can provide maximum accuracy of passenger information for further processing of the obtained statistical data of the studied system of public transport. The information obtained by organoleptic means was entered for further processing in the special accounting map, then calculations were performed for traffic areas between the stopping points of each studied route. Findings. The results of field research using the model of discomfort allow us to correctly predict the choice of mode of transport and the behaviour of passengers when using public transport in medium-sized cities. It is proved that the artificial underloading of the vehicle to avoid tight contact of passengers does not affect the level of infection with the virus of COVID-19 and, therefore, this restriction is not appropriate. Conclusions. Formation of the strategy of passengers' transportation in the conditions of COVID-19 is possible only with the use of the characteristic indicators of the transportation of people established by the multi-criteria analysis of a transport network - the level of discomfort, vehicle filling factor, the average time of transportation, the average distance of transportation. It is obligatory to use such means of protection as masks and gloves, provide the enhanced ventilation of the salon, and organize passengers' boarding through the back door with $100 \%$ contactless fare payment.

Key words: COVID-19, transport policy, safety, passenger comfort.

\section{Introduction}

Despite the convenience of passengers, during a pandemic, safety is a key factor in demand for public transport and such an indicator as convenience in Ukraine is always neglected when designing transport systems in medium-sized cities, although passengers' choice of public transport depends on many factors.

In order to increase the level of safety, as well as reduce the level of discomfort in public transport, the transport service should be designed so that compliance with the expectations of passengers was as adequate as possible [1-4].

Today, the authorities often recommend that urban passenger transport fill the bus cabin only in accordance with the maximum number of passengers provided for by the design of the vehicle.

This loading of the vehicle to avoid tight contact of passengers will have a positive effect on the load of the metal structure and the chassis, the axles expand the comfort zones of tire oscillations, increasing the service life of vehicles [5-9]. 
In public transport, in particular in medium-sized cities, according to the classification of DBN B.2.2-12: 2019, in a pandemic COVID-19, there are significant complications from the standpoint of optimizing transportation processes based on the maximum safety of passengers and drivers. According to NACTO [1012], transport authorities in the world are at the forefront to respond to a pandemic by rational developing a dynamic policy of rapid response to the transportation of people, especially in this emergency. According to the study by a group of Chinese government epidemiologists, including $\mathrm{Hu}$ Shixiong, the leading author of the study who works for the Hunan Provincial Centre for Diseases Control and Prevention, published by Stephen Chen in "Practical Preventive Medicine" and the South China Morning Post printed edition of March 9, 2020 [13-15], it was found that SARS-CoV2 can be in the air of the cabin and on the surfaces of the vehicle on which the respiratory drops of the infected person have settled for several days, significantly increasing the risk of its further transmission to the passengers by tactile [10].

The time SARS-CoV2 stays on a hard surface depends on such factors as temperature and surface type, for example, at $37{ }^{\circ} \mathrm{C}$, it can stay for two to three days on glass, fabric, metal, plastic or paper [16], which is a big problem.

It is necessary to form a policy of urban public transport in the conditions of COVID-19 by developing adequate measures to avoid spreading of COVID-19 with a sufficient level of comfort indicators with the strategies necessary for safe passengers' transportation in the cities [17].

An adequate level of travel comfort when using public transport in the design of the city's transport network is almost always neglected, especially when transporting the population by public transport in the medium-sized cities, believing that such an indicator as driving time will be the only one that will affect the passengers' choice [18-19].

\section{Methodology}

The article forms the basis for measuring the subjective passengers' perception of the quality of travel and proposes an improved policy of urban public transport in COVID-19 with an assessment of the level of discomfort in the public transport system of the medium-sized cities using multiple qualitative and quantitative indicators. The study provides a deeper understanding of the passengers' subjective attitude to the perception of the quality of transport services as a convenience factor in ensuring the appropriate level of safety in terms of a pandemic in public transport services. It is important that the research of passenger flows on bus routes of the city public transport in Ternopil was carried out as continuous full-scale research by a tabular method.

To carry out the analysis, we examined six rotating trips on each operating route of the city transport network in the periods of peak morning - from 6.30 to 10.00 , inter-peak - from 10.00 to 16.00 , peak evening - from 16.00 to 19.30 .

The peculiarities of passenger flow change by hours of the day, days of the week, uneven movement of passengers in time and space in the city from the initial to the final stop, as well as the main transfer points of the city, method of payment for the travel: cash, contactless or preferential. The research period is 7 calendar days, from 04.11.19 to 11.11 .19 , changes in passenger traffic are studied separately on weekdays and weekends. Time: 6.30-19.30. There was one accountant sitting in the cabin behind the back door of the bus working in the route vehicle starting from the first stop (Fig. 1). All received data on passenger turnover and method of payment, as well as the information on the type of transport on which the study was conducted, route number, the direction of the vehicle movement direct or reverse direction, start and end time, the time of the bus between stops, rolling stock, were written down by the accountant into the account card formed by the researchers.

On the territory of Ukraine, there are about 66 cities which can be classified as medium-sized [20], the area of the cities with a population of 50.000-250.000 people is up to 65 square kilometres. For a city like Ternopil, the main passenger flows are characterized by diametrical or radial directions, the population density is within 113.1 people/sq $\mathrm{km}$. According to the municipality [21-22], the city has 38 transport districts, the total number of public transport bus routes is 37 , they are served by 197 buses, the number of stopping points is 218 , and the total length of the bus route network is $647.7 \mathrm{~km}$.

The conducted research has established that the bus fleet of public transport is equipped with small passenger vehicles such as "Bogdan A092", "Etalon", each of which has a capacity of 42 passengers. During peak hours, traffic congestion was observed throughout the public transport network - the filling factor was more than $100 \%$, and the average daily ratio was in the range of $60-80 \%$.

The studies of the public transport network of Ternopil have identified the main basic indicators of passenger mobility, which may be characteristic of 
medium-sized cities, which correlates well with [19], for example, over zero, fewer than 45 , ideally 16 . This is the number of minutes that workers would prefer to spend commuting, according to various studies. So:

- speed of passenger inflow to a stop in between peak periods -1 pas/min., in peak hours -4 pas/min.:

- vehicle waiting time - up to 10 minutes;

- travelling time from peripheral areas to the centre - 30-35 minutes;

- travelling time between peripheral areas - up to 60 minutes;

- peak hours - 8.00-9.00, evening - 16.30-18.30;
- the estimated speed of passengers' moving in the city buses $-15-20 \mathrm{~km} / \mathrm{h}$.

The study was conducted in two stages - in-house and experimental - the collection and processing of the data obtained from the survey of passenger flows. Continuous field research was conducted by a tabular method which, in comparison with the existing ones, is the most time-consuming, but the only one that can provide maximum accuracy of passenger information for further in-house processing of the obtained statistical data of the studied system of public transport bus routes in Ternopil.

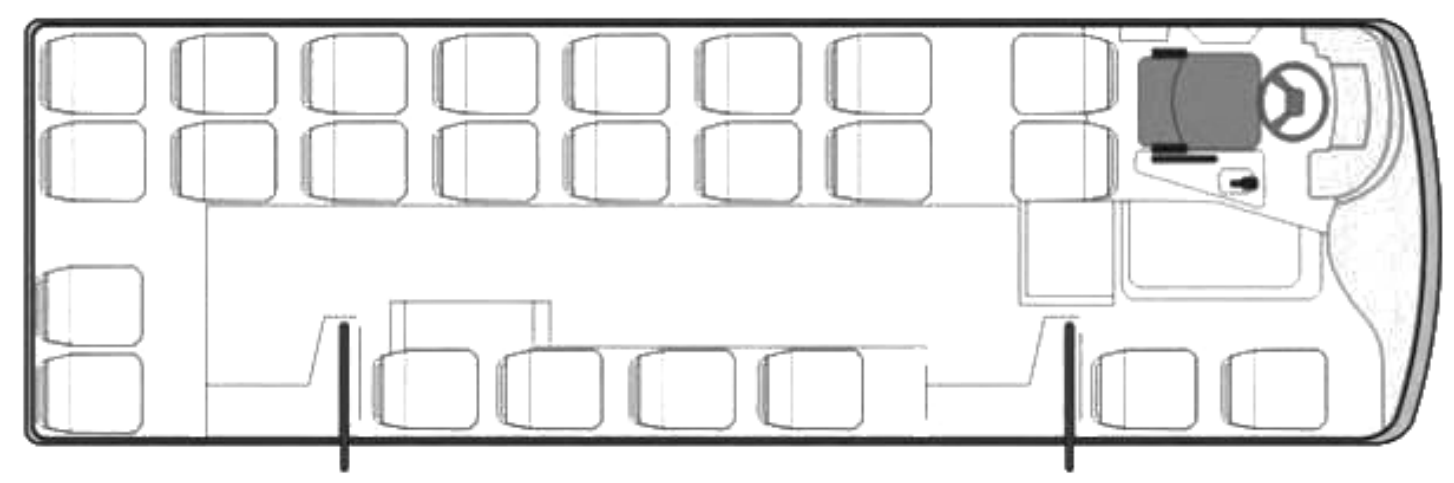

Fig. 1. Location of the accountant in the cabin of the bus Bogdan A092

The information obtained by organoleptic means was entered for further processing in the formed special accounting map, then calculations were performed for traffic areas between the stopping points of each studied route. The studies have shown that the degree of contactless (bank cards, Google Pay) payments ranged from $60 \%$ to $74 \%$ of the total number of passengers who paid the fare, except privileged categories of the population, in passenger transport on public transport routes in the city. It was determined that the time of vehicle movement between the sections of the routes, for all the subjects, was within 2-2.3 minutes, depending on the traffic situation, where the boundaries of the sections are public transport stops. A multi-criteria analysis of the transport network established that the coefficient of passengers' transfer is 1.1 ; coefficient of nonlinearity 1.76; the average waiting time - 5.8 minutes; route coefficient -4.60 ; the average travel time -33 minutes; the average distance of movement $-4.3 \mathrm{~km}$, which correlates with the data obtained a little earlier [22].

\section{Results and Discussion}

Optimal for the formation of urban public transport policy in terms of COVID-19 from the standpoint of optimization by the criterion of maximum safety at the rational loading is the use of the research data of the route which is the most difficult from the standpoint of maximum loading (Fig. 2, 3) and transportation time which limits the simultaneous stay of people in a closed space - the cabin of the route vehicle. For this route, the coefficient of nonlinearity, the average waiting time, the average travel time, the average travel distance are higher than the aboveaverage values. It is established that this is route №18 which connects two peripheral areas on the diametrically opposite sides of the city of Ternopil. The length of the route is $18.87 \mathrm{~km}$, the time of the trip in one direction is 53 minutes and the working time is from 6.20 to 20.50 .

The scheme of the vehicle interior - Bogdan A092 with a capacity of 42 seats, of which 25 seats are for seating, including the driver, is shown in Fig. 4. In [1], the overcrowding function as a function of discomfort is calculated considering the passenger capacity of vehicles, the number of seats and the duration of the trip. Different travel options were considered. With the first option, there were no free seats, with the second, there was one seat and with the third option, the passenger capacity of the vehicle due to a large number of passengers was used $100 \%$. In work [23] it is proposed to estimate the overcrowding by measuring its level by the value of the load factor and the number of standing passengers per square meter, although this figure is often standardized and taken into 
account by vehicle manufacturers at the design stage. Even if one conditional threshold value is exceeded, the discomfort function will grow exponentially [23]. It may

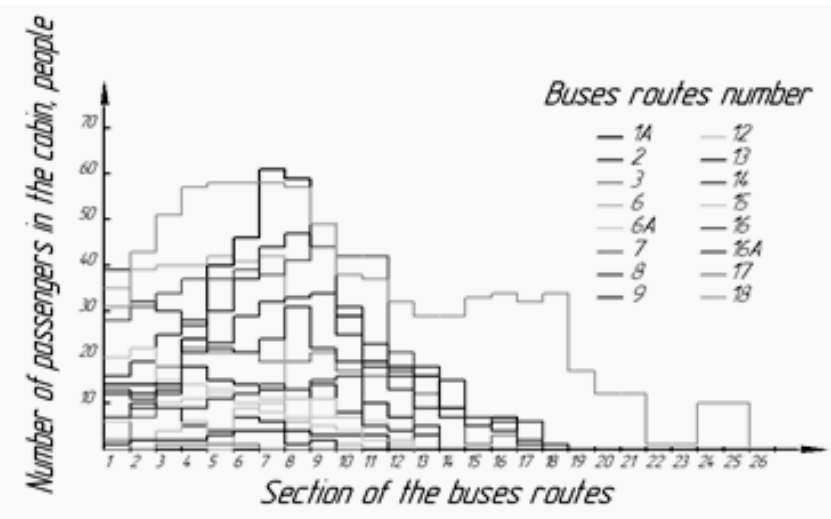

also be rational to approximate the law of change of the discomfort function by a polynomial of the third (fourth) degree modelling this situation.

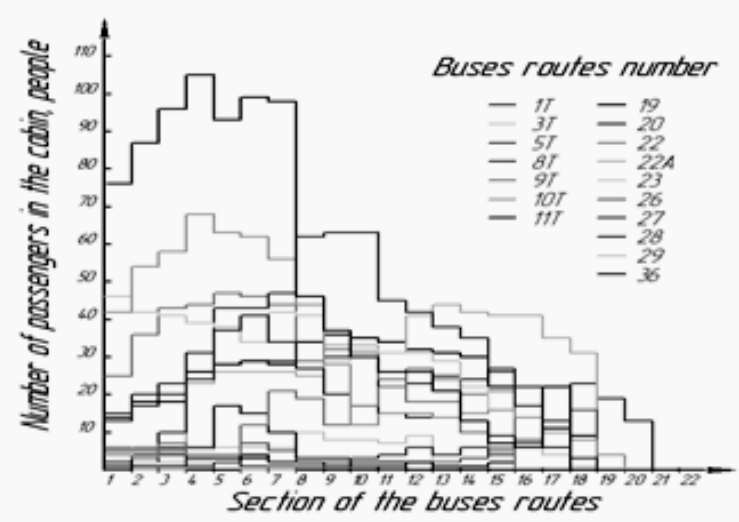

Fig. 2. Uneven passenger traffic for the specified vehicle by sections of the direct trip
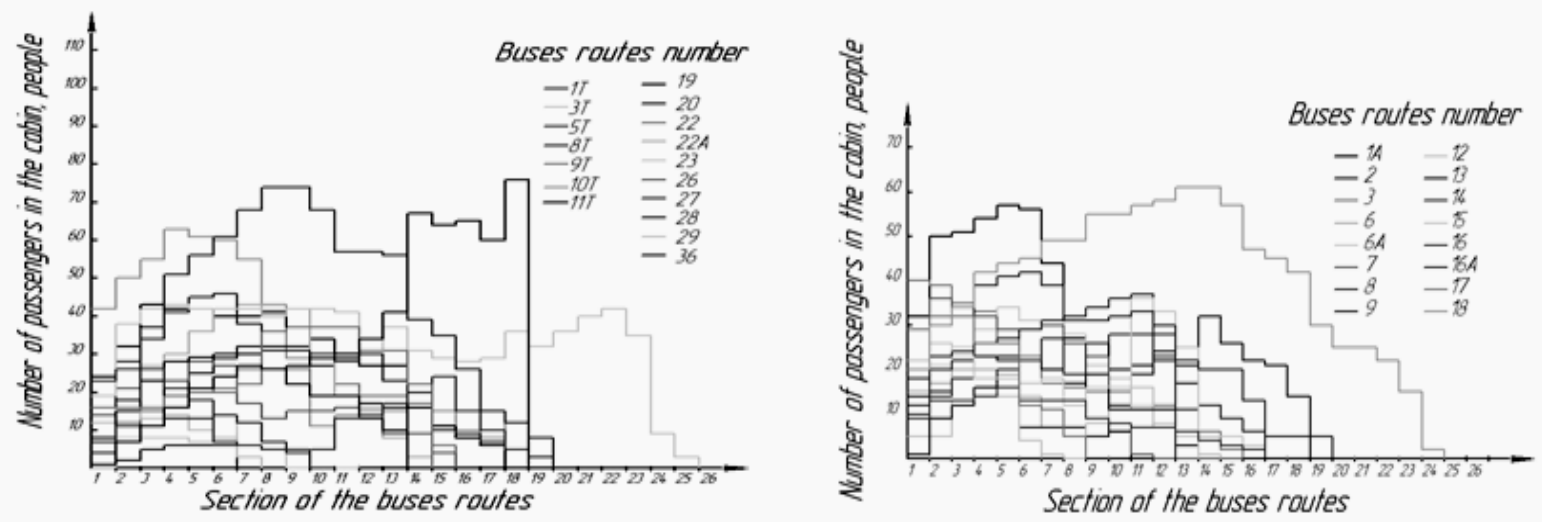

Fig. 3. Uneven passenger traffic for the specified vehicle by sections of the return trip

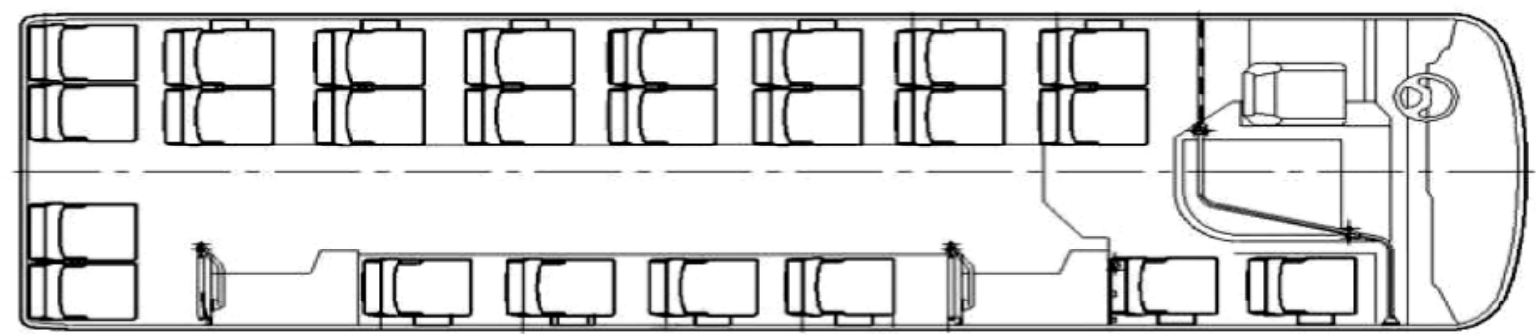

Fig. 4. Salon bus small vecicle capacity

The level of discomfort, Fig.4 and Fig. 5, is a function of the estimated density of passengers in the vehicle [17].

$$
X= \begin{cases}\alpha & \alpha \leq 1 \\ e^{\alpha} & \alpha>1\end{cases}
$$

where the level of the number of passengers in the vehicle $(\mathrm{x})$ is calculated based on the indicator $\alpha$

$$
\alpha=\frac{\text { Number of passengers in the vecicle }}{\text { Vecicle capacity }}
$$

For further assessment of discomfort, the known methods for determining the importance weigh are recommended, the function will acquire a piecewise linear shape, the level of total discomfort of passengers in the cabin of the vehicle during transportation [17].

$$
f\left(x_{t}\right)=\sum_{i} w_{i} \cdot x_{i t}
$$

where $x_{i t}$ is the value of the $\mathrm{i}$-th determinant of discomfort in the $t$-th time count, $w_{i}$ is the value of the $\mathrm{i}$ th weighting factor, xit is calculated from (1).

Forming the importance of weights, the authors believe that the weight for safety during transport in a COVID-19 pandemic is not acceptable for assessing 
discomfort according to (3) because it is dominant in the passenger's decision before the trip "this-that" to go or not to drive this vehicle. According to the researchers who conducted the survey in Ternopil, it was found that when choosing a passenger vehicle, as well as the possible route, a comfortable seat is an important indicator as the interviewed passengers wanted to travel less standing in the cabin. Taking into account the survey data, as well as the research data of Şükrü İmre and Dilay Çelebi, the value of Seat comfort 0.0556 was adopted for us, which obviously correlates with Seat comfort 0.0615 for T1 and Seat comfort 0.0762 for M2 [17].

Therefore, the following values were chosen: crowdedness - 0.4053; air-temperature in - 0.2243; seat comfort - 0.0556; information and guidance 0.0590 ; cleaning - 0.1324; physical condition 0.0899; vehicle breakdown 0.0335 [17]. Component analysis of the level of discomfort, respectively, of the routes of the public passenger transport network, was carried out for the routes on which the conditional threshold value equal to 1 was exceeded (Fig. 5): 1A, 8, 18, 22.
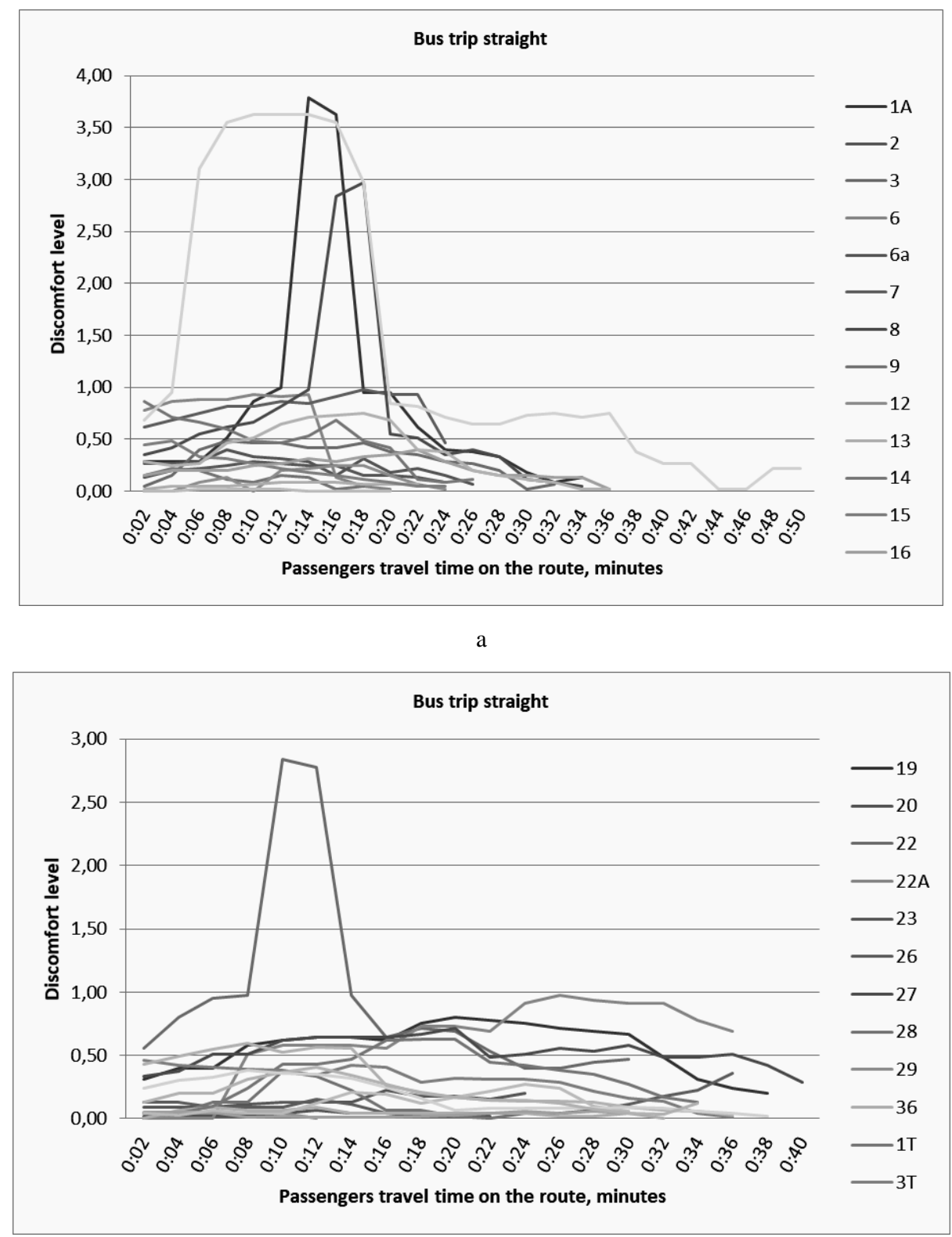

Fig. 5. The general level of discomfort as a function of passenger density over time when traveling on a public passenger transport in direct routes

In the implementation (3), Fig. 6, a component analysis investigated the functions of discomfort during travelling by the studied routes of the specified mode of transport for direct and return trips. The functions of 
discomfort levels during typical trips are shown in Figure 5. As can be seen from the graphs, the quantitative indicators on the magnitude of discomfort vary the most depending on crowdedness in a vehicle, air temperature, and seat comfort. Also, when planning urban passenger traffic after the pandemic, it is advisable to take into account the fact established by the study (Sekulić et al., 2016): in transport planning, time spent on commuting is traditionally considered as a waste that should be minimized - fast and efficient transport remains the goal of planners.

While innovations like the hyperloop and driverless vehicles promise ever-increasing frictionless travel, more and more academic research has challenged this perspective and highlighted the intrinsic value of mobility
(Sekulić et al., 2016). Our survey provides further confirmation of the intrinsic value of mobility: $69 \%$ of respondents stated they miss at least some aspects of commuting. The main aspects missed by respondents include the activity of commuting itself ( $53 \%$ ), the ability to spend some time alone ( $25 \%$ ), and feeling independent $(24 \%)[18,24]$. Thus, the demand for passenger transport by public transport will not change significantly.

$\mathrm{Hu}$ Shixiong, the lead author of the study, who works for the Hunan Provincial Center for Diseases Control and Prevention, claims that the sick passenger (Fig. 7, red figure) had no communication with other passengers during the four-hour trip. In the bus with a capacity of 48 seats, all windows were closed and the closed heating system was working [12-13].

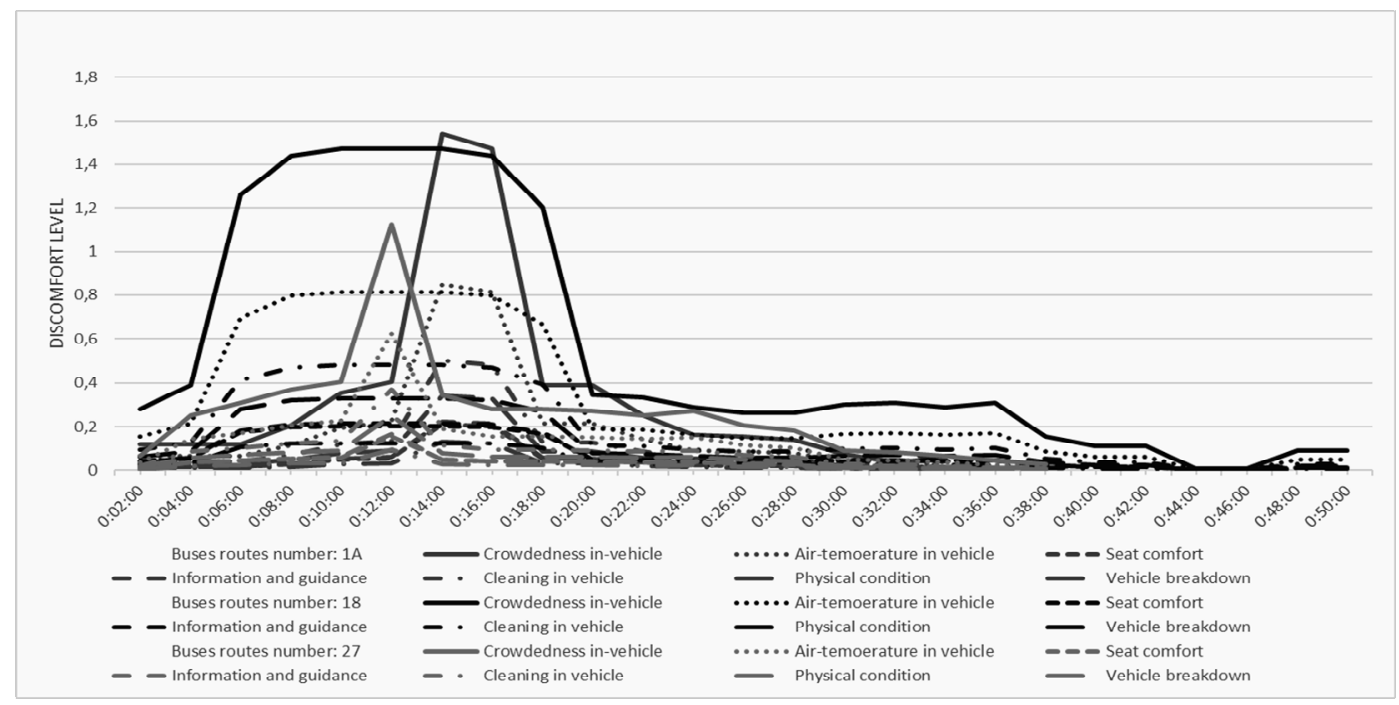

Fig. 6. Comparative analysis of the level of discomfort over time in a trip on the route of buses $1 \mathrm{~A}, 18$ and 27

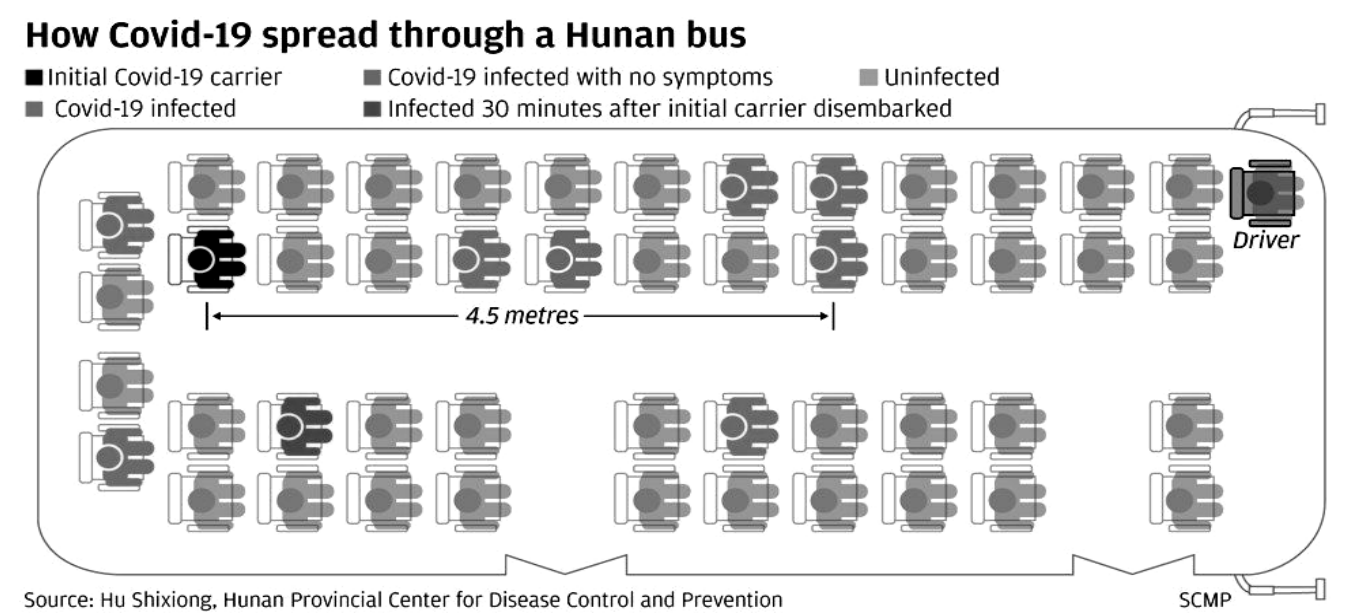

Fig. 7. The scheme of distribution of SARS-CoV2

The air route is characterized by the release of a finely dispersed aerosol, for example during exhalation, which can circulate in the air in contrast to the bulk aerosol, which almost immediately falls under the action 
of gravity on the ground or other objects. This transmission mechanism is the most controversial. At the beginning of the pandemic, scientists claimed that the virus was transmitted by droplets, the air route was practically not considered. With the accumulation of knowledge, the results of research, scientists are increasingly inclined to think about the reality of this method of transmission. The medical journal JAMA Internal Medicine published the results of research by the Center for Disease Prevention and Control of the People's Republic of China, which confirmed this version of the spread of coronavirus. Buses can be considered as a conditionally closed room with poor ventilation and air circulation. The virus is accumulated in the air, and accordingly the chances of getting infected by air increase [25].

In public transport, a sick person without any protection can infect other people by coughing, sneezing or other actions accompanied by the release of aerosols, even if they use means of protection. Drops can get directly on the mucous membranes of passengers, or indirectly through contact with parts and structures of the vehicle on which the aerosol with the virus got, followed by contact with the mucous membranes.

Considering the filling of the vehicles, the length of stay, especially during rush hour, passengers without protective equipment become potentially contact. This concept includes:

- direct physical contact with a probable or confirmed case of Covid-19

- unprotected contact (without the use of personal protective equipment) with mucous secretions from the air routes of a patient with Covid -19

- contact with a patient with Covid-19 at a distance of up to one meter for 15 minutes without the use of personal protective equipment or with suspicion of improper use

- $\quad$ staying indoors with a patient with Covid -19 for 15 minutes or more at a distance of less than one meter.

At a contact way of transfer, it is necessary to consider the possible time of existence of a virus on various surfaces. Scientists are discussing this issue, research gives ambiguous results because the conditions and methods of research differ. If you take the average duration, the virus can live on banknotes and glass for up to 4 days, plastic, stainless steel - 2-3 days, fabrics up to 2 days. Accordingly, for the safety of people, it is necessary to reduce the number of passengers to the level of seats provided by the design of the bus. Mandatory disinfection, frequent ventilation. And most important is the use of respiratory protection (mask, respirator), gloves, hand washing and disinfection.
Research [26] determined that by the time the bus stopped at the next stop the virus had affected seven other passengers, a characteristic feature is that the infected were not the only people that were relatively close to the patient, but also others that were at a distance from 0 to 4.5 meters. Although well known and proven, it is believed that the transfer of COVID-19 in the air at such distances is limited because tiny droplets of moisture from the breath produced by the affected people quickly fall down (Fig. 9, figures yellow) (Chen, S., 2020). The vast majority of passengers (grey) were not infected, even those who were sitting around the sick. After about 30, in the opposite direction on the same bus, other passengers, one of which was sitting in the front row on the opposite side of the aisle, were infected. It was approved [26] that a possible cause was breathing aerosols from the air without a protective mask. The passengers from the previous trip were infected in a fully enclosed space. The air flow is largely due to warm air from a working air conditioner, so hot air can transport droplets of the virus to a distance of 4.5 meters. Also, the mentioned studies found (Chen, S., 2020) that the first infected passengers after leaving the bus got on another bus which carried out the following trip within one hour resulting in two other passengers being infected by COVID-19. One of them was at a distance of 4.5 meters from the carrier of infection. At the time of the end of the study, he had infected 13 passengers. It was, proven, that the passengers who were sitting directly close to the carriers of SARS-CoV2, for unknown reasons, were not infected, although obviously they were exposed to the greatest effects of the aerosols from COVID-19. The studies have shown that none of the passengers who were not wearing masks in two buses, has been infected. SARS-CoV2 may be in the air for up to 30 minutes with the moving air up to 4.5 metres which is further than "a recommended safe distance of 1.8 meters" [26-27].

\section{Conclusions}

The need for the mobility of the population of the city is one of the basic needs that must be met. In a pandemic caused by COVID-19, there are considerable difficulties from the point of view of ensuring the highest level of passengers' safety and the driver subject to a satisfactory comfort level. The results of field studies, using a model of discomfort, allow correct predicting the choice of mode of transport and the behaviour of passengers when using public transport, particularly in medium-sized towns. The rational solution is to adapt the technology of transportation in a pandemic COVID-19 through the development of a dynamic policy rapid response for transportation of people specifically for that emergency with a reduction 
of risk for passengers and drivers, but not complete or partial, as in some countries. Considering the performance of passenger traffic transport network typical for medium-sized cities, established by the multicriteria analysis - the level of discomfort, the filling factor of the vehicle, the average time of transportation, the average distance of transportation, the maximum blocking of the spread of COVID-19, it is possible to ensure the formation of an adequate situation, the strategy of passenger transportation. It is necessary during passenger traffic to observe the filling of the bus salon only in accordance with the provided design of vehicle seats with the maximum number of passengers, as it was proven by the research, an artificial underloading of the vehicle to avoid the tight contact of the passengers does not influence the level of infection with COVID-19, so this limitation is not appropriate. It is mandatory to use such means as masks and gloves, enhance ventilation, as well as organize landing and disembarkation of passengers through the rear door of the bus for maximum protection of the driver with a mandatory $100 \%$ contactless payment that really will provide a high level of passengers' protection.

\section{References}

[1] Palma A., Kilani, M., Proost, S.: Transportation Research Part B, 2014, 1.

[2] Moroz M. M., Korol S. O., Boiko Y. O.: Actual Problems Of Economics, 2016, 1, 385.

[3] Boreiko O., Teslyuk V.: 12th International Scientific and Technical Conference on Computer Sciences and Information Technologies (CSIT 2017), Ukraine 2017, 1,113 .

[4] Bashutska O., Panchuk, N.: Simulation of Optimal Routes Passenger Transport. Update, 2, 5.

[5] Maslak O. I., Moroz O. V., Moroz M. M.: Actual Problems Of Economics, 2014, 10, 239.

[6] Lytvynenko I. V., Maruschak P. O., Lupenko S. A., Popovych P. V.: Materials Science, 2016, 52(1), 113.

[7] Petraška A., Čižiūnienè K., Jarašūnienė A., Maruschak P., Prentkovskis O. : J. of Business Economics and Management, 2017,18(6), 1098.

[8] Popovych P. V., Lyashuk O. L., Shevchuk O. S., Tson, O. P., Poberezhna L. Y., Bortnyk I. M.: INMATEH-Agricultural Engineering, 2017, 52(2), 113.

[9] Yavorskyi A. V., Karpash M. O., Zhovtulia L. Y., Poberezhny L. Y., Maruschak P. O., Prentkovskis O.: Proceed. of the 20th International Scientific Conference Transport Means,2016,370.
[10] Crowley F., Daly H., Doran J., Ryan, G.: COVID-19, Social Distancing, Remote Work And Transport Choice (No. SRERCWP2020-4). SRERC Working Paper Series, 2020.

[11] de Haas M., Faber R., Hamersma M.: Transportation Research Interdisciplinary Perspectives, 2020, 100150.

[12] Du Z., Wang L., Cauchemez S., Xu X., Wang X., Cowling B. J., Meyers L. A... Emerging infectious diseases, 2020, 26(5), 1049.

[13] Jin Y. H., Cai L., Cheng Z. S., Cheng H., Deng T., Fan Y. P., Han Y.: Military Medical Research, 2020,7(1), 4.

[14] Lai S., Leone, F., Zoppi C.: TeMA-Journal of Land Use, Mobility and Environment, 2020, 231.

[15] Zheng R., Xu Y., Wang W., Ning G., Bi Y.: Travel Medicine and Infectious Disease, 2020.

[16] World Health Organization.. Coronavirus disease 2019 (COVID-19): Situation report, 88.

[17] Şükrü İmre, Dilay Çelebi: Transportation Research Procedia, 2017, 25, 2441.

[18] Sekulić D., Dedović V., Rusov S., Obradović, A., Šalinić S.: Int. J. Ind. Ergon, 2016, 53, 328.

[19] Sokil B., Lyashuk, O. L., Sokil M., Popovich P. V., Vovk Y. Y., Perenchuk O. Z.: International Journal of Automotive and Mechanical Engineering ,2018,15(1), 4880.

[20] Burkina N., Furman T., Soboń J., Sapun K.: Financial Internet Quarterly, 2020, 16(2), 73.

[21] Boreiko O., Teslyuk V.: 12th International Scientific and Technical Conference on Computer Sciences and Information Technologies (CSIT), 2017, 1, 113.

[22] Borysova T., Monastyrskyi G.: Marketing and Management of Innovations, 2018, 3, 229.

[23] Qin F.: Hindawi Publishing Corporation Mathematical Problems in Engineering, 2014, 1.

[24] Rubin O., Nikolaeva A., Nello-Deakin S., te Brömmelstroet M.: What can we learn from the COVID-19 pandemic about how people experience working from home and commuting?. Centre for Urban Studies, University of Amsterdam, 2020.

[25] Shen Y., Li C., Dong H. et al.: JAMA Intern Med. Published online September 01, 2020. doi:10.1001/ jamainternmed.2020.5225

[26] Chen S.: Coronavirus can travel twice as far as official 'safe distance' and stay in air for 30 minutes, Chinese study finds. South China Morning Post. March, 9, 2020. https://www.scmp.com/news/china/science/article/30743 51/coronavirus-can-travel-twice-far-official-safedistance-and-stay

[27] Crema E.: Not even the air of empty spaces is coronavirus free (Two meters is not a safe distance). preprint arxiv:2006.08823., 2020. 